\section{Lower Cretaceous Lepidoptera}

LEPIDOPTERA are rare in the fossil record and, until relatively recently, most fossil butterflies and moths had been found in Tertiary deposits. Records of Lepidoptera from earlier in the fossil record have been discounted ${ }^{1}$. The first evidence of a Cretaceous lepidopteran was Mackay's description ${ }^{2}$ of the head of a caterpillar in amber (about $72 \mathrm{Myr}$ BP). Kühne described micropterigid scales from Cretaceous resin (about $100 \mathrm{Myr}$ BP) from West France ${ }^{3}$, and several lepidopterous specimens have been found in Canadian and Siberian ambers of Cretaceous age (personal communication from A. Mutuura and A. Skalski), There is doubt about a much earlier record reported by Riek ${ }^{4}$. who described two insects from Triassic beds in South Africa and placed them in the Paratrichoptera, which he considered a suborder of the Lepidoptera. (Evidence to suggest that this material is not lepidopterous will be published elsewhere.) Thus the four moths described here, which were found in Lebanese amber dating from at least $100 \mathrm{Myr} \mathbf{B P}$, are the earliest indisputable lepidopterous specimens.

The amber was received from Professor Aftim Acra in Beirut. It was considered Aptian ${ }^{5}$ or Neocomian ${ }^{6}$ but must be at least 100 Myr BP, and Schlüter ${ }^{7}$ has suggested an absolute age of $130 \mathrm{Myr}$ BP. The moths (Fig. 1) have a wingspan of about

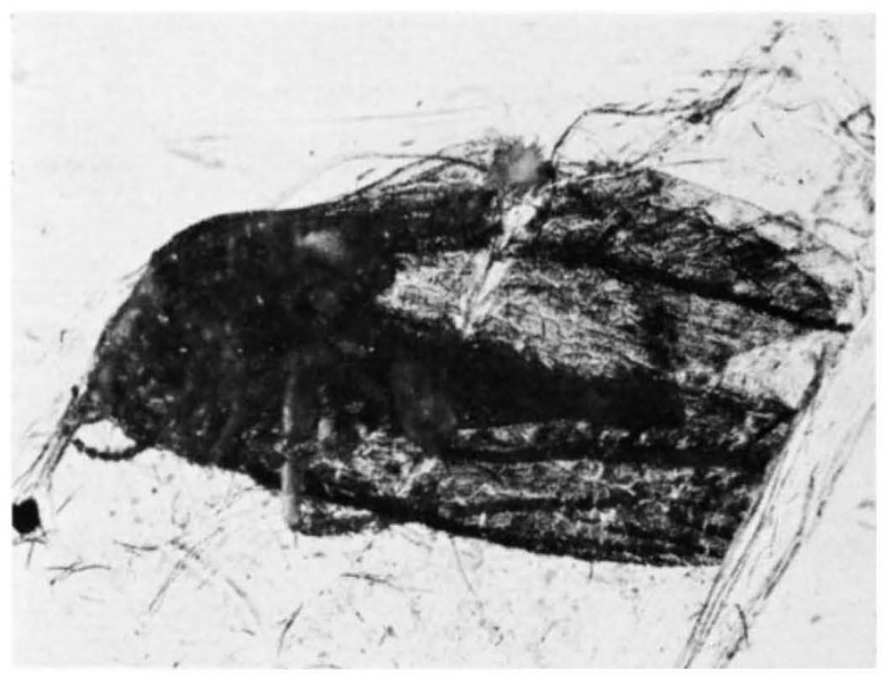

Fig. 1 Lower Cretaceous resin with lepidopterous inclusion. (Photo: British Museum Natural History.)

$10 \mathrm{~mm}$ and have proved to be similar to extant species of Micropterigidae (Lepidoptera, Zeugloptera). They have been compared with recent species of Zeugloptera and with the primitive Dacnonypha, Agathiphagidae. The fossil moths have similarly shaped wings and wing scales, with abundant microtrichia on the wing membrane, comparable with recent micropterigids such as Sabatinca and Micropterix. The mouthparts have mandibles but no proboscis, and maxillary and labial palps similar to those of Sabatinca and Micropterix. Differences between the fossil and living species include the lack of ocelli and the apparent absence from the fossil forewing of a branch of the subcostal vein. The fossil moths have scales and an epiphysis on the foretibia, both of which are typical lepidopterous characters. Although the jugum cannot be seen in the fossils there is a small frenulum with four bristles similar to that of recent Sabatinca. A study of recent micropterigids shows that the fossil species is close to Sabatinca with which it has more characters in common than with Micropterix.

Re-examination of the holotype of Micropterix pervetus Cockerell $^{8}$ from Burmese amber of Miocene age (about $7 \mathrm{Myr}$ BP) shows that this species should be transferred to Sabatinca. Similarly Micropterix proavitella Rebel $^{9}$, described from Baltic amber (Eocene/Oligocene, about $40 \mathrm{Myr}$ BP) should also be transferred to Sabatinca. The genus Sabatinca has extant species in Australia, New Zealand and New Caledonia and its former distribution and origins can now be traced back through Burma in the Miocene, Northern Europe in the Eocene/ Oligocene to probable origins in the Lower Cretaceous in the Lebanon. The Australasian species of Sabatinca are relicts of a former much wider distribution.

The newly discovered fossil provides evidence of Lepidoptera in the Lower Cretaceous but, because of its relatively specialised morphology, I propose an earlier date for the separation of the Lepidoptera from the Trichoptera-Lepidoptera stem-group than the Cretaceous origin suggested previously. We should now be looking for fossil evidence of Lepidoptera in the Jurassic. A fuller account of the morphology and relationship of these Lower Cretaceous fossil moths will be published elsewhere.

Paul Whalley

\section{Department of Entomology,}

British Museum (Natural History),

Cromwell Road, London, UK

Received 12 November 1976; accepted 28 February 1977.

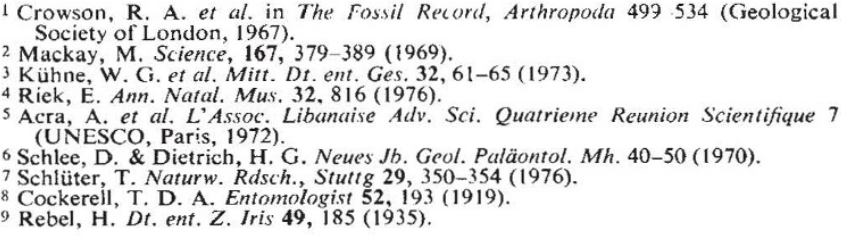

\section{Photoperiodic termination of diapause in spider mites}

TERMINATION of diapause in the spider mite Tetranychus urticae is considered to depend solely on a period of chilling, the so-called cold rest ${ }^{1-3}$. The minimal period of chilling required to reactivate a certain percentage of the overwintering population may vary between populations of different geographic origin ${ }^{4}$. No unambiguous relationship, however, has been established between chilling period and latitude, for there may be appreciable differences in the minimal period of cold rest between strains from close localities ${ }^{5}$. The situation seemed more complex after Dubynina ${ }^{6}{ }^{6}$ discovery that reactivation of a Russian strain of this species increased linearly with time when mites had been induced to diapause under the influence of long days, abrupt temperature changes and severe competition for food, while reactivation was cyclical when diapause had been induced by short days and relatively low temperatures. In the latter case maximal percentages of reactivating females were obtained after diapausing mites had been kept in cold storage for 40 and $75 \mathrm{~d}$. Minimal percentages were obtained after 50 and $95 \mathrm{~d}$. Reactivation was complete by about the 105th day of storage. Experiments in England, however, produced no evidence for cyclical reactivation in British strains of $T$. urticae ${ }^{5}$. Using a Dutch strain of $T$. urticae, which has a constant photoperiodic reaction and has been reared in the laboratory for more than $15 \mathrm{yr}$ (ref. 7), we have now found that termination of diapause in this species depends not only on a period of chilling but on photoperiod as well.

Female mites were induced to diapause at $18^{\circ} \mathrm{C}$ in a short-day photoperiod of 10L:14D and then stored at $4{ }^{\circ} \mathrm{C}$, in either a longday regime of $16 \mathrm{~L}: 8 \mathrm{D}$ or a short-day regime of $10 \mathrm{~L}: 14 \mathrm{D}$. At regular intervals samples of about 50 diapausing mites were retrieved from this cold storage and their capacity to terminate diapause was tested by placing them on fresh bean leaves at three different temperatures (Fig. 1). Females were considered to have reactivated if, within $10 \mathrm{~d}$, their colour had changed from the bright orange-red of the overwintering form to the yellowish-green of the 'summer' form, and feeding and oviposition had started. Photoperiod was constant during this test; mites which had been stored in the cold in the long-day regime were reactivated in the 